\title{
Solubility and trapping of helium in apatite
}

Peter K. Zeitler $^{\mathrm{a} *}$, Eva Enkelmann ${ }^{\mathrm{a}, 1}$, Jay B. Thomas ${ }^{\mathrm{b}, 2}$, E. Bruce Watson ${ }^{\mathrm{b}}$, Leonard D. Ancuta ${ }^{\mathrm{a}}$, and Bruce D. Idleman ${ }^{\mathrm{a}}$

${ }^{a}$ Department of Earth and Environmental Sciences, Lehigh University, Bethlehem, PA 18015, USA

${ }^{b}$ Department of Earth and Environmental Sciences, Rennselaer Polytechnic Institute, Troy, NY 12180, USA

*Corresponding author: peter.zeitler@lehigh.edu

Present addresses:

${ }^{1}$ Department of Geology, University of Cincinnati, Cincinnati, OH 45221, USA nm

${ }^{2}$ Department of Earth Sciences, Syracuse University University, Syracuse, NY 13244, USA

\begin{abstract}
A fundamental but unquantified assumption in $\mathrm{U}-\mathrm{Th} / \mathrm{He}$ dating of apatite is that grains do not incorporate extraneous helium by solution or other processes, but large age dispersion seen in some samples suggests that this assumption might be violated. Our laboratory experiments show that helium solubility in apatite is quite low and unlikely to lead to age dispersion in most samples. However, in some samples highly variable and sometimes large helium uptake suggests that apatite grains can trap helium in microvoids that could be derived from fluid inclusions or other microstructures, a conclusion supported by crushing and step-heating experiments. The presence of such microvoids raises the possibility that closure and age systematics could be complicated either by trapping of internally generated radiogenic helium and/or alteration of helium diffusion kinetics by impeding diffusion.
\end{abstract}

Keywords: Helium, apatite, solubility, diffusion, thermochronology

\section{INTRODUCTION}

U-Th/He dating of apatite (Zeitler et al., 1987) has become a widely-used tool in studies of tectonic and surface processes because radiogenic ${ }^{4} \mathrm{He}$ diffusion remains significant at temperatures well below $100^{\circ} \mathrm{C}$. Considerable progress has been made in understanding the kinetics of helium diffusion (e.g., Farley, 2000; Shuster et al., 2006) as well as the systematics of the U-Th/He method (e.g. Ketcham et al., 2011; Brown et al., 2013). Lately, a considerable

page 1 
amount of work has been focused on understanding second-order age dispersion seen in many samples, especially those from slowly cooled rocks. Plausible explanations include grain-size effects (Farley, 2000), inadvertent analysis of crystal fragments (Brown et al., 2013), problems with the alpha-ejection correction related to $U$ and Th zoning (Farley et al., 1996), external implantation of ${ }^{4} \mathrm{He}$ (Spiegel et al., 2009), presence of mineral inclusions (Farley, 2002), and in particular, the systematic alteration of diffusion behavior due to radiation-damage traps (Farley, 2000; Shuster et al., 2006). Nonetheless, for some samples showing dispersed ages these explanations still fall short.

As currently practiced the $\mathrm{U}-\mathrm{Th} / \mathrm{He}$ method assumes that helium solubility in apatite is sufficiently low that samples contain no initial ${ }^{4} \mathrm{He}$, and violations of this assumption could be an additional source of age scatter. The assumption is rooted in the belief that helium solubility in apatite should be very low, as is true for the other noble gases in other minerals. The observation that many samples do give meaningful and replicable ages supports a low value for helium solubility. However, trapped ${ }^{4} \mathrm{He}$ could plausibly become an issue in some environments: although the concentration of helium in air is only about 5 ppm (Ozima and Podosek, 2002), concentrations in some crustal reservoirs like natural-gas accumulations are much higher (10's of ppm to several percent; Zartman et al., 1961), and in low-permeability metamorphic settings local ${ }^{4} \mathrm{He}$ partial pressures might become significant.

In this paper, we report our attempts to determine helium solubility in apatite and the implication of our results for apatite $\mathrm{U}-\mathrm{Th} / \mathrm{He}$ geochronology. Our work stemmed from a separate project on the effect that fission tracks have on helium diffusion. That project required that we anneal all radiation damage from samples before irradiating them to create induced fission tracks, but because such annealing outgasses all ${ }^{4} \mathrm{He}$, we needed to return helium to samples which we attempted by soaking them at high partial pressures. Our trial runs on unirradiated samples thus provided us the opportunity to study helium solubility in apatite. One unexpected outcome of our work is that while the intrinsic solubility in apatite does appear to be very low $\left(<2.3 \times 10^{-11}\right.$ mol/g-bar), even apparently "high-quality" crystals can incorporate significant amounts of helium in what we hypothesize to be fluid inclusions or other structures that represent microvoids, making the effective solubility much higher in some cases. This phenomenon in turn 
provides an additional explanation for $\mathrm{U}-\mathrm{Th} / \mathrm{He}$ age scatter as well as raising questions about the systematics of ${ }^{4} \mathrm{He}$ diffusion behavior during slow cooling.

\section{METHODS}

\subsection{Materials}

Most of our experiments used aliquots of Durango apatite standard (Young et al., 1969), a fluorapatite with an unusual $\mathrm{Th} / \mathrm{U}$ ratio of $\sim 20$ and a rather high effective uranium concentration (eU) of $\sim 50 \mathrm{ppm}(\mathrm{eU}=\mathrm{U}+0.235 \mathrm{Th})$. Durango apatite formed in a quickly cooled geological setting and bracketing ${ }^{40} \mathrm{Ar} /{ }^{39} \mathrm{Ar}$ ages establish its age as $31.44 \pm 0.18 \mathrm{Ma}(2 \sigma)$ (McDowell et al., 2005). Optically clear fragments of Durango are commonly used as a laboratory standard and yield kinetic results consistent with volume-diffusion behavior that correspond to a slow-cooling closure temperature of $\sim 70{ }^{\circ} \mathrm{C}\left(10^{\circ} \mathrm{C} / \mathrm{m} . \mathrm{y} ., 80 \mu \mathrm{m}\right.$; Farley, 2000). The Durango working standard that we used in our experiments comprises $\sim 180-250 \mu \mathrm{m}$ internal fragments obtained from a large centimeter-sized gem-quality crystal. Some of our experiments also used aliquots of apatite grains taken from our archive of dated samples, and information about these can be found in the relevant data tables and references. Table 1 provides a summary of sample information and Table A4 provides U-Th/He analytical data for previously unpublished ages.

Table 1. Sample information

\begin{tabular}{|c|c|c|c|}
\hline Sample & $\begin{array}{c}\mathrm{eU} \\
(\mathrm{ppm})\end{array}$ & $\begin{array}{l}\sim \mathrm{R}_{\mathrm{s}}{ }^{1} \\
(\mu \mathrm{m})\end{array}$ & U-Th/He ages of aliquots \\
\hline \multicolumn{4}{|c|}{ Gem-quality standard } \\
\hline Durango & $\sim 45$ & 190 & \\
\hline \multicolumn{4}{|l|}{ Slowly cooled ${ }^{2}$} \\
\hline $\mathrm{NC} / \mathrm{MM} 4 \mathrm{a}^{3}$ & 11 & 105 & $33,64,71,72,83,84 \mathrm{Ma}$ \\
\hline \multicolumn{4}{|c|}{ Slowly cooled; dispersed ages } \\
\hline $\mathrm{NC} / \mathrm{SY} 2 \mathrm{AB}^{3}$ & 7 & 90 & $66,111,132,143,147,152,183,219 \mathrm{Ma}$ \\
\hline \multicolumn{4}{|c|}{ Quickly cooled; good replication } \\
\hline NB-36-26 & 14 & 95 & $5.6,5.6,6.2 \mathrm{Ma}$ \\
\hline GAM209 ${ }^{5}$ & 77 & 100 & $5.9,6.0,6.3,6.6 \mathrm{Ma}$ \\
\hline SN15 ${ }^{5}$ & 25 & 85 & $9.5,9.6 \mathrm{Ma}$ \\
\hline \multicolumn{4}{|c|}{ Quickly cooled; dispersed ages } \\
\hline NB- $07-26^{4}$ & 30 & 105 & $11.0,13.7,24.6 \mathrm{Ma}$ \\
\hline
\end{tabular}

\subsection{Solubility Experiments}


Apatite fractions from samples Durango, NC/MM-4a, and NC/SY-2AB were outgassed of their radiogenic ${ }^{4} \mathrm{He}$ by heating to $\sim 450^{\circ} \mathrm{C}$ for 24 hour, and were then treated in two ways at very different helium partial pressures. Initial sample runs at relatively low partial pressures of 5 to 10 mbar (low $\mathrm{P}_{\mathrm{He}}$ ) were done at Lehigh University by flooding our helium extraction system with high-purity ${ }^{4} \mathrm{He}$ and measuring pressure using the extraction line's capacitance manometers (MKS model 627B; quoted accuracy of $\pm 0.15 \%$ ). For these runs, outgassed samples were placed in the crucible of a double-vacuum resistance furnace and heated to temperatures of between 200 and $900{ }^{\circ} \mathrm{C}$ while they were exposed to ${ }^{4} \mathrm{He}$ for durations of 0.2 to 32 hours. When measurements showed that negligible helium was being taken up at these low pressures, we carried out additional high $\mathrm{P}_{\mathrm{He}}$ "soaking" runs at Rensselaer Polytechnic University using a system in which outgassed samples in small quartz boats were heated in a cold-seal vessel pressurized with $~ 12$ and 100 bar of pure helium gas, at temperatures around $650^{\circ} \mathrm{C}$ and durations of $\sim 930$ to 1850 hours. For all but a few of the low- $\mathrm{P}_{\mathrm{He}}$ experiments, temperatures and durations of the runs were easily sufficient to allow complete equilibration of grain interiors by diffusion: using Durangoapatite kinetics of $33 \mathrm{kcal} / \mathrm{mol}$ and $\mathrm{D}_{\mathrm{o}} / \mathrm{a} 2$ of 50 (Farley, 2000), a large grain $100 \mu \mathrm{m}$ in radius would be more than $99 \%$ equilibrated within 1 hour at $650^{\circ} \mathrm{C}$, or 12 hours $400^{\circ} \mathrm{C}$. We omit any data from the few trial runs that would not have equilibrated during soaking.

${ }^{4} \mathrm{He}$ contents for both single-grain and multi-grain apatite aliquots were measured using an allmetal extraction line that includes a sample dropper, the double-vacuum resistance furnace, capacitance manometers, SAES GP50 getter, and reference pipettes for ${ }^{4} \mathrm{He}$ concentration and ${ }^{4} \mathrm{He} /{ }^{3} \mathrm{He}$ discrimination. This line supplies gas to a Pfeiffer QMS 200 quadrupole mass spectrometer. Apatite samples were loaded in small Pt and later in $\mathrm{Nb}$ tubelets, placed into the sample dropper, pumped down and baked overnight at $\sim 50^{\circ} \mathrm{C}$, then dropped into the furnace. Using this system, our observed precision on age for repeated analyses of Durango apatite is about $2.5 \%$ ( $1 \sigma$ standard deviation), and our typical uncertainties for ${ }^{4} \mathrm{He}$-abundance measurements are $1-2 \%$. For the ${ }^{4} \mathrm{He}$ amounts reported in this paper, uncertainties for most analyses of low- $\mathrm{P}_{\mathrm{He}}$ runs are about $25 \%(1 \sigma)$, and for high- $\mathrm{P}_{\mathrm{He}}$ runs $1-2 \%$.

\subsection{Crushing Experiments}


To gain insight into the locations of helium taken up by our samples, we performed a series of crushing analyses on weighed aliquots of previously outgassed and subsequently ${ }^{4} \mathrm{He}$-soaked Durango fragments, as well as both ${ }^{4} \mathrm{He}$-soaked and natural samples with varying geologic histories. Following crushing, a weighed subset of each aliquot was analyzed by heating to determine the amount of remaining ${ }^{4} \mathrm{He}$. The crusher used a modified Varian all-metal mini valve in which a conical nose piece attached to the valve driver engages with the sample within a conical receptacle (Fig. A.1); this device was fixed to the standard helium extraction line. When fully engaged, the crusher's nose piece left a dead volume in the receptacle, so in order to cause significant crushing to take place, it was necessary to process large $\sim 2-10 \mathrm{mg}$ aliquots containing hundreds of grains. As a result, it was not feasible to hand-pick grains using the criteria normally applied to dated samples, so in particular for the non-Durango aliquots, even though they were $100 \%$ pure apatite separates, it is likely that non-optimal grains were included. Also, while a significant fraction of each sample was reduced to a fine powder, each aliquot was not crushed to the same degree. Therefore the reported size of the "mechanical" gas fraction released by crushing should be viewed as a minimum and qualitative measure.

\subsection{Size Analysis}

To assess how thoroughly each aliquot was crushed, we analyzed the size distribution of crushed samples using tools available in the ImageJ software package (Rasband, 2015). This involved using alcohol to disperse the crushed sample on a glass slide, digitally photographing the sample, and then analyzing the images. Because the finest material tended to clump, data from these size analyses likely underestimate the volume of the finest size fractions.

\subsection{Step-Heating Analysis}

Several samples were step-heated in the resistance furnace to further examine how ${ }^{4} \mathrm{He}$ release occurs from our samples. This furnace is not ideal for accurate kinetic measurements at low temperatures because actual temperatures within the lined crucible are lower by perhaps $\sim 35^{\circ} \mathrm{C}$ than temperatures observed with the external thermocouple used to control the process temperature. Also, the thermal mass in the system leads to a sluggish response to changes in temperature, particularly below $\sim 500^{\circ} \mathrm{C}$. However, performance of the system is consistent, so although our results might not be accurate, within-sample step-heating patterns should still be 
valid. Based on analyses of unmodified Durango apatite shards we found that to first order, using temperatures corrected for the average offset, our kinetic data are close to those reported by Farley (2000; see below) when grain-size differences are taken into account. On plots showing kinetics we use corrected-temperature data to facilitate general comparison, but we caution against using our data for quantitative purposes.

\section{RESULTS}

\subsection{Apparent Solubility Measurements}

Fig. 1 and Table A.1 present the results of our apparent solubility measurements (determined by dividing measured ${ }^{4} \mathrm{He}$ content by applied ${ }^{4} \mathrm{He}$ pressure, normalized by mass). At the lower helium partial pressures applied in our extraction line, virtually all measurements were indistinguishable from line blanks (Fig.1a,b) although there does seem to be somewhat more scatter than would be expected. At the much higher values of $\mathrm{P}_{\mathrm{He}}$, we did observe significant helium uptake but the salient observation is the enormous scatter in the data (Fig. 1c,d). 

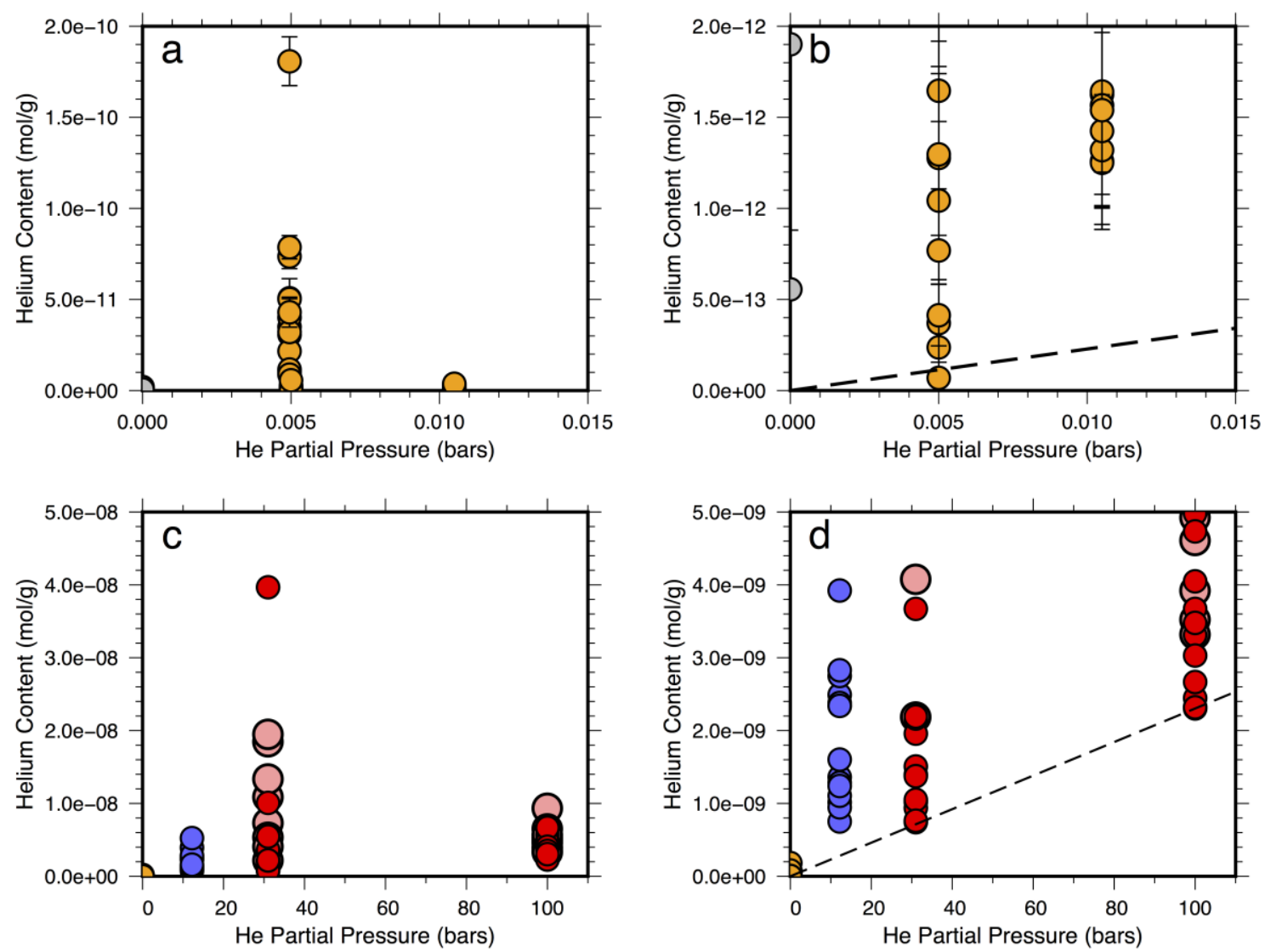

Figure 1. Helium solubility measurements in apatite. Gray - blank measurements; Orange - low- $\mathrm{P}_{\mathrm{He}}$ experiments using multigrain aliquots of Durango apatite; Blue - High $\mathrm{P}_{\mathrm{He}}$ experiments using single grains of samples MM-4a and NC/SY2A,B (McKeon et al., 2014); Pink - High $\mathrm{P}_{\mathrm{He}}$ experiments using multigrain aliquots of Durango apatite; Red - High $\mathrm{P}_{\mathrm{He}}$ experiments using single grains of Durango apatite. Panels a and $\mathrm{c}$ show overview of results from low- and High $\mathrm{P}_{\mathrm{He}}$ runs; panels $\mathrm{b}$ and $\mathrm{d}$ show details at lower apparent solubilities. Dashed line shows Henry's Law trend defined by lowest solubilities obtained from the high- $\mathrm{P}_{\mathrm{He}}$ data.

Initially we used multi-grain aliquots, given the small signals observed in the low- $\mathrm{P}_{\mathrm{He}}$ runs, but when we observed the large scatter we repeated measurements using only single grains to try to better understand this dispersion. As expected, the single-grain measurements show both a wider range in helium contents and a greater number of grains with lower values. Similar behavior is observed in aliquots of high-quality Durango apatite grains as well as natural samples.

\subsection{Crushing Measurements}

Table A2 shows the size analysis of our crushed multigrain aliquots. Generally the crusher produced very fine powders consistent with a power-law distribution if one accepts that the finer grain sizes are under-represented due to clumping. We can make a simple rough estimate of the 
amount of "mechanical" release of lattice-sited helium, if we make two assumptions: (1) that all of the helium located within one unit-cell dimension from a fragment's surface will be released by crushing, and (2) that the crushed fragments are cubes. This estimate will clearly be a function of average fragment size. For a release distance equal to a unit-cell size of $10 \AA ̊$ over which helium will be mechanically released, and a fragment size of $1 \mu \mathrm{m}$, the predicted mechanical release is $0.6 \%$; using a larger value of $30 \AA$ as the release distance and $0.1 \mu \mathrm{m}$ as the fragment size, the predicted release is $18 \%$. Using the observed size distribution for all the samples and a release distance of $10 \AA$, the average predicted mechanical release from lattice sites is $\sim 3 \%$.

Table 2 shows the results of crushing runs on large multi-grain aliquots. Samples of pristine Durango standard as well as more quickly-cooled apatites that have good age replication all show minimal amounts of mechanical helium release ( 0.5 to $3.4 \%)$, consistent with our rough estimate of mechanical release of a small amount of lattice-sited helium ( $3 \%$ or less). In contrast, we observed significantly greater amounts of mechanical helium release from the soaked samples (16.5 to 53.9\%), the "bad-actor" quickly cooled natural sample having large age dispersion (53.3\%), and the slowly cooled natural samples (6.4 to 9.55\%; Table 2). 
Table 2. Summary of Crushing Experiments

\begin{tabular}{|c|c|c|c|}
\hline Sample & $\begin{array}{l}\text { Mechanical } \\
{ }^{4} \mathrm{He}(\mathrm{mol} / \mathrm{g})^{\mathrm{a}}\end{array}$ & $\begin{array}{c}\text { Thermal } \\
{ }^{4} \mathrm{He}(\mathrm{mol} / \mathrm{g})^{\mathrm{b}}\end{array}$ & $\begin{array}{l}\text { Fraction } \\
\text { Mechanical (\%) }\end{array}$ \\
\hline \multicolumn{4}{|c|}{ Outgassed then soaked } \\
\hline Durango & $5.44 \mathrm{e}-10$ & $2.76 \mathrm{e}-09$ & $16.5 \%$ \\
\hline Durango & $6.71 \mathrm{e}-09$ & 7.14e-09 & $48.4 \%$ \\
\hline \multicolumn{4}{|l|}{ Soaked } \\
\hline $\mathrm{NC} / \mathrm{SY} 2 \mathrm{AB}$ & $1.00 \mathrm{e}-08$ & $9.20 \mathrm{e}-09$ & $52.1 \%$ \\
\hline NC/MM4a & $7.85 \mathrm{e}-09$ & 4.44e-09 & $63.9 \%$ \\
\hline \multicolumn{4}{|c|}{ Fast cooling, dispersed ages } \\
\hline NB-07-26 & $2.13 \mathrm{e}-09$ & $1.87 \mathrm{e}-09$ & $53.3 \%$ \\
\hline \multicolumn{4}{|c|}{ Slow cooling, dispersed ages having some eU correlation } \\
\hline $\mathrm{NC} / \mathrm{SY} 2 \mathrm{AB}$ & $1.08 \mathrm{e}-09$ & $1.03 \mathrm{e}-08$ & $9.5 \%$ \\
\hline \multicolumn{4}{|c|}{ Slow cooling, good age replication } \\
\hline $\mathrm{NC} / \mathrm{MM} 4 \mathrm{a}$ & $5.30 \mathrm{e}-10$ & 7.71e-09 & $6.4 \%$ \\
\hline \multicolumn{4}{|c|}{ Fast cooling, good age replication } \\
\hline Durango std. & $5.03 \mathrm{e}-11$ & $9.57 \mathrm{e}-09$ & $0.5 \%$ \\
\hline NB-36-26 & $1.38 \mathrm{e}-11$ & $5.26 \mathrm{e}-10$ & $2.6 \%$ \\
\hline GAM209 & $7.39 \mathrm{e}-11$ & $2.66 \mathrm{e}-09$ & $2.7 \%$ \\
\hline SN15 & $3.57 \mathrm{e}-11$ & $1.01 \mathrm{e}-09$ & $3.4 \%$ \\
\hline
\end{tabular}

${ }^{\mathrm{a}}{ }^{4} \mathrm{He}$ released by crushing at room temperature

${ }^{\mathrm{b}} \mathrm{H} \mathrm{He}$ released by standard heating at $1150^{\circ} \mathrm{C}$, after crushing

\subsection{Step-Heating}

Samples of both untreated and soaked Durango apatite standard displayed the Arrhenius behavior reported in previous studies: a linear trend early in the release of ${ }^{4} \mathrm{He}$, followed by a modest rollover to lower slopes at higher temperatures, starting in the range $300^{\circ} \mathrm{C}$ to $400^{\circ} \mathrm{C}$ (e.g., Farley, 2000; Fig. 2; Table A3). An aliquot of a well-behaved natural sample that shows good age replication (GAM212) also behaved this way. In sharp contrast, two natural samples that yield poor age replication (NB-07-26 and NB-54-26) showed markedly non-linear Arrhenius behavior caused by significantly deferred released of ${ }^{4} \mathrm{He}$. 


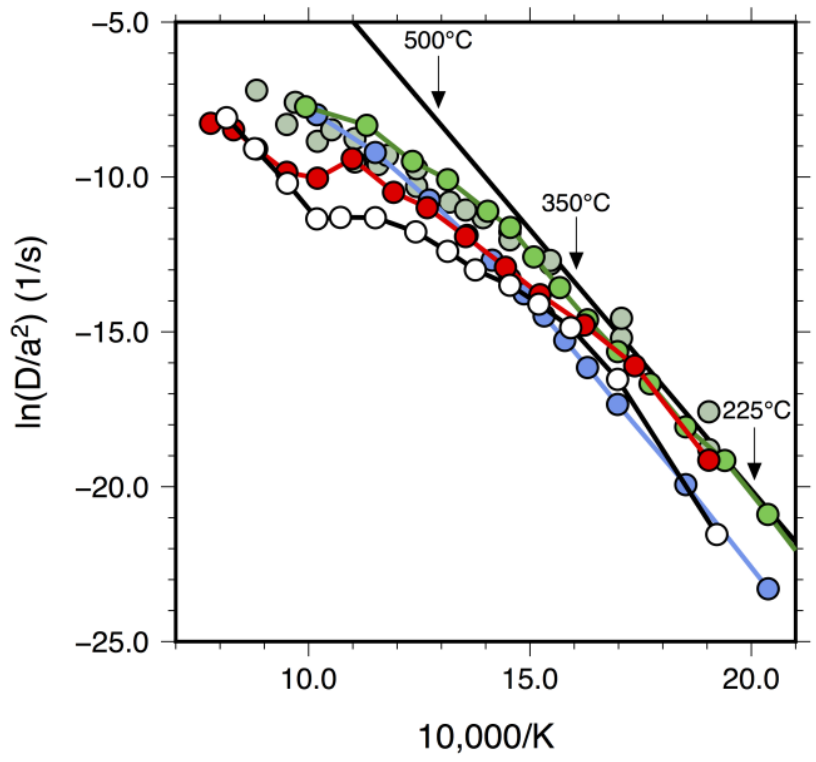

Figure 2. Arrhenius plot show results from apatite step-heating experiments. Durango apatite - bright green: natural sample; pale green: outgassed then soaked. Well-replicated natural sample (GAM212; see Table 3) - blue. Poorly replicated natural samples showing significant mechanical helium release - white: NB-07-26 (see Table 3); red - NB-54-26 (see Table 3). Black shows trend of lower-temperature measurements reported by Farley (2000).

\section{DISCUSSION}

\subsection{Solubility of ${ }^{4} \mathrm{He}$ in Apatite}

The lowest solubility values we observed display a systematic increase in helium uptake consistent with Henry's Law (Fig. 1a,d). Using the lowest helium uptake measured for a single grain at 100 bars, we obtain a maximum solubility estimate of $\sim 2.3 \times 10^{-11} \mathrm{~mol} / \mathrm{g}$-bar, for a temperature of $650^{\circ} \mathrm{C}$. Solubility is a function of temperature but in minerals this relationship is potentially complicated and in any case poorly known (Ozima and Podosek, 2002). Given the large scatter in our data, we cannot draw any experimentally-based conclusions about the temperature dependence of helium solubility in apatite. Therefore, one caveat regarding our results is that solubility might be different at temperatures closer to the helium closure interval, where diffusion is still sufficiently rapid to equilibrate samples. Nevertheless, our results provide a concrete measurement important in understanding and calculating the mass balance and systematics of noble-gas partitioning in crustal rocks (Baxter, 2003).

\subsection{Origins of Scatter, Helium Soaking Experiments}


Clearly processes beyond simple Henry's-Law solubility are controlling the uptake and retention of helium in our samples. Beyond the extreme scatter seen in our uptake data, the behavior of samples showing significant mechanical release of helium and delayed release of helium during step-heating also requires explanation. External contamination seems unlikely as helium is only loosely adsorbed on grain surfaces (Ozima and Pososek, 2002) and our mechanically released component survived pumping during overnight bakeouts at $\sim 50^{\circ} \mathrm{C}$. It is worth noting that Protin et al. (2016) reported observations of a more retentive form of adsorption of atmospheric helium on the surface of olivine grains, and most of our experiments were not capable of distinguishing the locations within grains of the helium uptake that we saw. However, we think the large scatter in our data and the magnitude of the helium uptake rules out a significant grain-surface effect.

A plausible explanation that can address all of our observations can be found in the work of Watson and Cherniak (2003), who suggested that pores originating as fluid inclusions can serve as sinks for noble gases in quartz. The presence of such features could explain the large and variable helium uptake we saw in soaked apatite samples, the observation that significant helium in these samples is released by crushing, and the step-heating results. The scatter we observed in apparent helium uptake, greater for single grains, would reflect the differences in total pore volume within different grains, with the lowest degrees of uptake approaching that expected for sink-free grains. It is noteworthy that Lippolt et al. (1994) reported finding micron-scale pores apatite grains.

A possible challenge to this explanation is that most of our soaked samples were aliquots of our laboratory's gem-quality Durango standard, and were thus apparently imperction-free grains at the scale of optical inspection. However, the very high helium pressures applied during soaking would allow the total volume of pores to be quite small. Making the assumption that the pressure in a grain-interior void will eventually equilibrate with the applied partial pressure, at 100 bars of $\mathrm{P}_{\mathrm{He}}$ the pore volume needed to explain an uptake of $\sim 5 \times 10^{-9} \mathrm{~mol} / \mathrm{g}$ would be only $12 \mathrm{ppmv}$, equivalent to a single pore of diameter $\sim 5 \mu \mathrm{m}$ for a typical $100 \mu \mathrm{m}$ grain. This volume could be distributed over a large number of smaller imperfections, as nanometer-scale fluid inclusions certainly can occur (Bodnar, 2003), and Watson and Cherniak (2003) imaged pores in quartz ranging down to their detection limit of $\sim 10 \mathrm{~nm}$ in size; there is every reason to think that such pores occur below this observational limit. 


\subsection{Nature of pores}

Fluid inclusions and pores are certainly one possible means of developing voids capable of trapping ${ }^{4} \mathrm{He}$ and are certainly seen in apatite (e.g. Lippolt et al., 1994), but a variety of other features might also act as traps. Features as small as fission- and alpha track damage have been invoked to explain trapping and inhibition of apparent diffusivity (Farley, 2000; Shuster et al., 2006), so the full array of defects and dislocations commonly seen in apatite could also act in this fashion. Further experiments will be needed to examine uptake in the presence of various microstructures. For geochronological applications and for understanding the impact of nonradiogenic trapping artifacts, an important additional consideration to explore is the degree to which such features obey any sort of systematic kinetic relationship, or for the purposes of thermochronology are essentially a fixed characteristic inherited by a grain.

\subsection{Implications for U-Th/He Geochronology}

\subsubsection{Solubility and Excess He}

Our upper-bounds estimate for helium solubility suggests that the uptake of helium by apatite under normal crustal conditions prior to and during closure at $50-100{ }^{\circ} \mathrm{C}$ is unlikely to be a concern. This corroborates common experience that ignoring initial ${ }^{4} \mathrm{He}$ has no impact on calculated ages. At the earth's surface, with $\sim 5 \times 10^{-6}$ bar of atmospheric helium as the partial pressure, uptake through solution would be only $\sim 1 \times 10^{-16} \mathrm{~mol} / \mathrm{g}$ (assuming that diffusive equilibration could even occur). At pressures 1000 times higher, gas of atmospheric composition would lead to dissolved ${ }^{4} \mathrm{He}$ of $5 \times 10^{-13} \mathrm{~mol} / \mathrm{g}$, which for a typical apatite of $20 \mathrm{ppm} \mathrm{U}$, would amount to a trivial age difference of only $0.005 \mathrm{~m}$.y. It is also worth noting that high $\mathrm{P}_{\mathrm{He}}$ that was present only when temperatures were well above or well below closure would not impact samples: at high temperatures, any helium taken up from a pulse of high $\mathrm{P}_{\mathrm{He}}$ would diffuse back out; at low temperatures diffusion would be too slow to allow high $\mathrm{P}_{\mathrm{He}}$ to equilibrate with a grain. Thus, under normal crustal conditions in many geological environments helium uptake would be unlikely to lead to age dispersion.

It is possible that in a particularly helium-rich environment like a natural-gas reservoir, apatite helium ages could be affected. For example, if temperatures were high enough to permit 
diffusive equilibration in a gas reservoir having $5 \% \mathrm{He}$, and if the reservoir pressure were as high

as $1 \mathrm{kbar}, \mathrm{P}_{\mathrm{He}}$ would be 50 bars and the predicted uptake into an apatite grain would be $\sim 1 \times 10^{-9}$ $\mathrm{mol} / \mathrm{g}$. For an apatite having $20 \mathrm{ppm} \mathrm{U}$, helium uptake under such extreme conditions could produce an apparent age increase of $\sim 10$ m.y., which could be quite significant for younger samples.

\subsubsection{Direct Helium Trapping in Inclusions and Pores}

Although helium uptake by solution might not be an issue for routine $\mathrm{U}-\mathrm{Th} / \mathrm{He}$ systematics in apatite, our experiments suggest that trapping in fluid inclusions and other micro- and nanovoids could at times be a more serious problem. We observed significant mechanical release of helium from shards of gem-quality Durango apatite that appeared perfectly clear under optical inspection (in air, at 96X), and which were free of any radiation damage. In addition, several of our natural samples, which were more likely to have grains containing inclusions, also showed significant non-solution uptake. This suggests that small microvoids, whatever their origin, are likely to be present in many grains that are chosen for dating, and so most samples could potentially incorporate excess helium in such voids.

How could such microvoids impact age relationships? Most directly, simple trapping of fluids in inclusions could introduce excess helium into samples (e.g., Stockli et al., 2000). This has long been recognized as a concern and is one reason visibly inclusion-free samples are selected for U$\mathrm{Th} / \mathrm{He}$ dating. However, in gem-quality Durango apatite we observed significant uptake into what must have been volumetrically small voids, so while picking grains using optical criteria is an important filter, this might not guarantee elimination of any trapped helium because very small voids might still be present. This is probably not a large concern because high $\mathrm{P}_{\mathrm{He}}$ such as we used in our soaking experiments would be unlikely to occur in natural settings.

\subsubsection{Slow Cooling and Self-Contamination}

In the presence of small voids, the radiogenic helium produced within grains themselves could lead to more widespread issues in $\mathrm{U}-\mathrm{Th} / \mathrm{He}$ dating. At slow cooling rates of $1{ }^{\circ} \mathrm{C} / \mathrm{m}$.y. or less, an apatite sample could spend tens of millions of years or more in the closure interval. During such slow cooling or during near-isothermal residence in the partial retention zone, this radiogenic 
helium is ordinarily assumed to be partially or completely lost but could become trapped if microvoids are present. Given the low solubility for helium in apatite, entry into a void could amount to what is essentially a permanent one-way trap. Is this likely? Although our data are few, our crushing results from slowly cooled samples (Table 2) show that they can have unexpectedly high mechanical helium release.

The total path length for a typical diffusing helium atom will be on the order of meters before it escapes a grain (e.g. Glickman, 2000). As such the probability is high that newly formed radiogenic helium atoms will fall into voids during their random walk through the crystal lattice, even if the volume fraction of voids is small. Assuming a diffusion jump in apatite is as large as the unit cell dimension ( $\sim 10 \AA$; note that in the models of Djimbi et al. (2015) the jump distance is less), a helium atom near the center of a grain $50 \mu \mathrm{m}$ in radius will on average travel a total of 2.5 meters accumulated over the $5 \times 10^{9}$ jumps it requires to escape. The probability of any one jump ending in a void would be equal to the volume fraction of voids in the lattice, but for the total number of jumps, even for void fractions as low as $1 \mathrm{ppb}$ it would be almost certain that a diffusing helium atom would encounter a void and become trapped.

The trapping of radiogenic helium in this way would amount to a process of self-contamination. This phenomenon would be broadly similar to the radiation-damage trapping that is hypothesized to modify helium diffusion kinetics (Shuster et al., 2006). However, whereas radiation-damage accumulation and trapping is inherent to $\mathrm{U}-\mathrm{Th} / \mathrm{He}$ systematics (by radiogenic production and diffusion kinetics) and can be modeled quantitatively (Flowers et al., 2009), trapping in small voids could represent more of an extrinsic effect that will depend on the size and distribution of such microstructures. We propose that autogenic ${ }^{4} \mathrm{He}$ contamination is a likely explanation for the common observation that old, slowly cooled samples tend to yield larger age dispersion than younger more quickly cooled samples. For simple monotonic thermal histories involving fast and recent cooling, the amount of syn-closure radiogenic production (and thus trapping) would be low or negligible.

The extent to which such trapping could occur merits additional study. On the one hand, trapping might apply not just to ${ }^{4} \mathrm{He}$ produced during closure but also to that component produced earlier at substantially higher temperatures. On the other hand, trapping could be self-limiting if voids 
are only stable at lower temperatures or are small. For example, at $125^{\circ} \mathrm{C}$, a one cubic micron void could attain a pressure of 100 bars if it contained only $3 \times 10^{-15} \mathrm{~mol}$ of helium (equivalent to less than a million years of production from a $150-\mu \mathrm{m}$ radius grain having $20 \mathrm{ppm}$ of $\mathrm{U})$. At such pressures, some solution back into the grain would begin to occur.

At higher temperatures during our step-heating experiments on bad-actor samples, the excess helium content is eventually released in a progressive fashion and so must be returning to the crystal lattice where it can escape grains by diffusion (Figure 2). Whether this is due to solubility effects or to defect annealing is not known, but given the low solubility value we obtained, it seems unlikely that dissolution back into the grain is responsible.

\subsubsection{Modification of diffusion kinetics}

Even if partially retentive microvoids do not represent permanent sinks for diffusing helium atoms, they could act to impede diffusion within grains, thereby altering their kinetics. Unlike the simple case of trapping, to generally impede diffusion, microvoids would have to be abundant and more broadly distributed, and it seems more likely that dislocations and defects would act in this way than fluid inclusions.

Crystal imperfections and microvoids might be a more important and widespread contributor to helium diffusion systematics than realized. Experimental observations at the scale of whole grains (Shuster et al., 2006) suggest that activation energies for volume diffusion in apatite range from about 120 to $160 \mathrm{~kJ} / \mathrm{mol}$, with the range proposed to be due to radiation damage and with no apparent control by halogen content. Activation-energy measurements made at a far finer spatial scale by Cherniak et al. (2009) yielded a value of $117 \mathrm{~kJ} / \mathrm{mol}$, close to the low-radiationdamage end member reported by Shuster et al. (2006). However, lattice-scale theoretical simulations of volume diffusion in apatite predict substantially lower values of between about 95 and $105 \mathrm{~kJ} / \mathrm{mol}$ depending on anion composition (Djimbi et al., 2015). Possibly the difference between lattice calculations and observations on natural samples could be due to the presence of crystal imperfections. This might explain why eU-age correlations are often imperfect, in that radiation damage provides only part of the explanation for why volume diffusion in natural apatite grains can become impeded. 


\section{CONCLUSIONS}

Data from our laboratory experiments suggest that helium solubility in apatite is quite low (at $650^{\circ} \mathrm{C},<2.3 \times 10^{-11} \mathrm{~mol} / \mathrm{g}$-bar) and unlikely to contribute dispersion in the vast majority of samples dated using the U-Th/He method. The highly variable and in some cases large helium uptake we observed in some samples suggests that incorporation of helium into apatite grains can take place through trapping in microvoids that could be derived from fluid inclusions or other microstructures, a conclusion supported by crushing and step-heating experiments. The presence of such microvoids raises the possibility that closure and age systematics could be complicated either by trapping of internally generated radiogenic helium and/or alteration of helium diffusion kinetics by impeding diffusion. Further experiments are required to quantify the impact of microvoids and strain on diffusion, to explore the frequency with which grains contain helium that is not lattice-sited, to understand the frequency and distribution of small sub-micron fluid inclusions in apatite, and to understand the formation and annealing systematics of microstructures in apatites having various strain histories.

Acknowledgements. Funding: this work was supported by the Petroleum Research Fund [grant ACS PRF\# 46796-AC2 to PKZ] and the National Science Foundation [grant EAR-0948204 to EBW]. We thank Martin Danisik, Cécile Gautheron, and Joanne Wartho for thoughtful and thorough reviews.

\section{REFERENCES}

Baxter, E.F. (2003) Quantification of the factors controlling the presence of excess ${ }^{40} \mathrm{Ar}$ and ${ }^{4} \mathrm{He}$. Earth and Planetary Science Letters 216, 619-634.

Bodnar R.J. (2003) Introduction to fluid inclusions. In Fluid Inclusions: Analysis and Interpretation (eds. I. Sampson, A. Anderson and D. Marshall). Mineralogical Society of Canada, Short Course, 32, 1-8.

Brown R. W., Beucher R., Roper S., Persano C., Stuart F. and Fitzgerald P. (2013) Natural age dispersion arising from the analysis of broken crystals: Part I. Theoretical basis and implications for the apatite (U-Th)/He thermochronometer. Geochimica et Cosmochimica Acta 122, 478-497, doi:10.1016/j.gca.2013.05.041. 
Cherniak, D. J., Watson, E. B., and Thomans, J. B., 2009. Diffusion of helium in zircon and apatite. Chemical Geology 268, 155-166, doi:10.1016/j.chemgeo.2009.08.011.

Djimbi D. M., Gautheron C., Roques J., Tassan-Got L., Gerin C. and Simoni E. (2015) Impact of apatite chemical composition on (U-Th)/He thermochronometry: An atomistic point of view. Geochimica et Cosmochimica Acta 167, 162-176, doi: 10.1016/j.gca.2015.06.017.

Farley K. A. (2000) Helium diffusion from apatite: General behavior as illustrated by Durango fluorapatite. Journal of Geophysical Research 105, 2903-2914.

Farley, K. A. (2002) (U-Th)/He dating: Techniques, calibrations, and applications. Reviews in Mineralogy and Geochemistry 47, 819-844.

Farley, K. A., Wolf, R. A., and Silver, L. T. (1996) The effects of long a-stopping distances on (U-Th)/He ages. Geochimica et Cosmochimica Acta 60, 4223-4229.

Flowers R. M., Ketcham R. A., Shuster D. L., and Farley K. A. (2009) Apatite (U-Th)/He thermochronometry using a radiation damage accumulation and annealing model. Geochimica et Cosmochimica Acta 73, 2347-2365.

Glickman, M. E. (2000) Diffusion in Solids. Wiley, New York, 472 pp.

Kendrick M. A. and Burnard P. (2013) Noble gases and halogens in fluid inclusions: a journey through the Earth's crust. In The Noble Gases as Geochemical Tracers (ed. P. Burnard). Springer-Verlag, Berlin, pp. 319-369, doi: 10.1007/978-3-642-28836-4_11.

Ketcham R. A., Gautheron C. and Tassan-Got L. (2011) Accounting for long alpha-particle stopping distances in (U-Th-Sm)/He geochronology: Refinement of the baseline case. Geochimica et Cosmochimica Acta 75, 7779-7791, doi: 10.1016/j.gca.2011.10.011.

Lippolt, H.J., Leitz, M., Wernicke, R.S. and Hagedorn, B. (1994) (Uranium + thorium)/helium dating of apatite: experience with samples from different geochemical environments. Chemical Geology (Isotope Geoscience Sction) 112, 179-191.

McDowell F., McIntosh W. and Farley, K. (2005) A precise ${ }^{40} \mathrm{Ar}^{39}{ }^{39} \mathrm{Ar}$ reference age for the Durango apatite (U-Th)/He and fission-track dating standard. Chemical Geology 214, 249263.

McKeon R. E., Zeitler P. K., Pazzaglia F. J., Idleman B. D., Enkelmann, E. (2014) Decay of an old orogen: Inferences about Appalachian landscape evolution from low-temperature thermochronology. Geological Society of America Bulletin 126, 31-46, doi:10.1130/B30808.1. 
Ozima M. and Podosek, F. A. (2002) Noble Gas Geochemistry (2 ${ }^{\text {nd }}$. Edition). Cambridge University Press, Cambridge, 286 pp.

Protin, M., Blrad, P.-H., Marrocchi, Y. and Mathon, F. (2016) Irreversible adsorption of atmopsheric helium on olivine: A lobster pot analogy. Geochimica et Cosmochimica Acta 179, 76088, doi: 10.1016/j.gca.2016.01.032 .

Rasband W. S. (2015) ImageJ. U. S. National Institutes of Health, Bethesda, Maryland, USA, http://imagej.nih.gov/ij/, 1997-2015.

Spiegel, C., Kohn, B. P., Belton, D. and Gleadow, A. J. (2009) Apatite (U-Th-Sm)/He thermochronology of rapidly cooled samples: The effect of He implantation. Earth and Planetary Science Letters 285, 105-144.

Shuster D. L., Flowers R. M. and Farley, K. A. (2006) The influence of natural radiation damage on helium diffusion kinetics in apatite. Earth and Planetary Science Letters 249, 148-161.

Stockli, D.F., Farley, K.A., and Dumitru, T.A. (2000) Calibration of the apatite (U-Th)/He thermochronometer on an exhumade fault block, White Mountains, California. Geology 28 983-986.

Watson E. B. and Cherniak D. J. (2003) Lattice diffusion of Ar in quartz, with constraints on Ar solubility and evidence of nanopores. Geochimica et Cosmochimica Acta 67, 2043-2062, doi:10.1016/S0016-7037(02)01340-6.

Young E., Myers A., Munson, E. and Conklin, N. (1969) Mineralogy and geochemistry of fluorapatite from Cerro de Mercado, Durango, Mexico. U.S. Geological Survey Professional Paper 650-D, D84-D93.

Zartman R. E., Wasserburg G. J., and Reynolds, J. H. (1961) Helium, argon, and carbon in some natural gases. Journal of Geophysical Research 66, 277-306.

Zeitler P. K., Meltzer A. S., Brown L., Kidd W. S. F., Lim C. and Enkelmann, E. (2014) Tectonics and topographic evolution of Namche Barwa and the easternmost Lhasa Block. In Towards an improved understanding of uplift mechanisms and the elevation history of the Tibetan Plateau (eds. J. Nie, J., G. D. Hoke, and B. Horton). Geological Society of America Special Paper, 507, 23-58, doi: 10.1130/2014.2507(02).

Zeitler P. K., Herczeg A., McDougall I. and Honda, M. (1987) U-Th-He dating of Durango fluorapatite: a potential thermochronometer. Geochimica et Cosmochimica Acta 51, 28652868. 


\section{FIGURE CAPTIONS}

Figure 1. Helium solubility measurements in apatite. Gray - blank measurements; Orange low- $\mathrm{P}_{\mathrm{He}}$ experiments using multigrain aliquots of Durango apatite; Blue - High $\mathrm{P}_{\mathrm{He}}$ experiments using single grains of samples MM-4a and NC/SY2A,B (McKeon et al., 2014); Pink - High $\mathrm{P}_{\mathrm{He}}$ experiments using multigrain aliquots of Durango apatite; Red - High $\mathrm{P}_{\mathrm{He}}$ experiments using single grains of Durango apatite. Panels a and c show overview of results from low- and High $\mathrm{P}_{\mathrm{He}}$ runs; panels $\mathrm{b}$ and d show details at lower apparent solubilities. Dashed line shows Henry's Law trend defined by lowest solubilities obtained from the high- $\mathrm{P}_{\mathrm{He}}$ data.

Figure 2. Arrhenius plot show results from apatite step-heating experiments. Durango apatite bright green: natural sample; pale green: outgassed then soaked. Well-replicated natural sample (GAM212; see Table 3) - blue. Poorly replicated natural samples showing significant mechanical helium release - white: NB-07-26 (see Table 3); red - NB-54-26 (see Table 3). Black line shows trend of lower-temperature measurements reported by Farley (2000).

Figure A1. Images of device used for vacuum crushing. 1.33" min-conflat fitting gives scale. Note rounded end of nose piece (left) and amount of material needed to cause crusher to engage sample within receptacle (right). 